\title{
The role of gastro-esophageal reflux (GER) in systemic sclerosis and lung fibrosis
}

\author{
Angelo De Lauretis ${ }^{1,2}$ \\ Alfredo Chetta ${ }^{1}$ \\ 1 Department of Respiratory Medicine, University of \\ Parma, Parma, Italy \\ 2 Interstitial Lung Disease Unit, Royal Brompton Hospi- \\ tal, London, UK
}

Address for correspondence:

Angelo De Lauretis, MD

Interstitial Lung Disease Unit

Royal Brompton Hospital

Sydney Street, SW3 6NP, London, UK

Phone: 02073518327 - Fax: 02073518336

E-mail: angelo.delauretis@gmail.com

\section{Summary}

Systemic sclerosis (SSc) is an autoimmune condition characterized by tissue fibrosis of the skin and internal organs. A significant subgroup of SSc patients develops progressive interstitial lung disease (ILD) leading to pulmonary fibrosis similar to IPF (idiopathic pulmonary fibrosis). Gastro-esophageal reflux (GER) has been suggested as a driving factor in the pathogenesis of both SSc-ILD and IPF. The esophagus is affected in $50-82 \%$ of patients with SSc. Gastric reflux may be liquid, gaseous, or particulate; acid or nonacid; distal (localized to the distal oesophagus) or proximal (reaching the proximal oesophagus and pharynx). Reflux to the proximal oesophagus, which is intuitively linked to microaspiration into the lungs, appears to be quite common in patients with ILD-SSc and IPF. Importantly, a significant proportion of GER reflux is asymptomatic.

Concentration of pepsin and bile acids in bronchoalveolar lavage (BAL) and exhaled breath condensate (EBC) have been investigated as biomarkers of microaspiration in various respiratory diseases. The confirmation of a causative link of microaspiration in the genesis and progression of lung fibrosis would have a major impact in the management of ILD-SSc patients. It is likely that proteases such as pepsin, and not the acidity, are the primary target for future therapies. Potent inhibitors specific for proteases, e.g. pepstatin, are available and have been tested in phase-III clinical trials.

KEY WORDS: gastro-esophageal reflux, respiratory aspiration, microaspiration, pepsin, lung fibrosis, systemic sclerosis.

\section{Introduction}

Systemic sclerosis (SSc) is an autoimmune condition characterized by tissue fibrosis of the skin and internal organs. Progressive interstitial lung disease (ILD) occurs in a significant subgroup of patients, and is now the main cause of death in SSc. Pathogenetic pathways believed to be involved in SSc-ILD are complex and include endothelial
GER has been suggested as a driving factor in the pathogenesis of both SScILD and IPF. cell injury, inflammatory/immune activation and dysregulated fibroblast homeostasis (1). We have recently shown that a marker of epithelial cell permeability, such as inhaled technetium-99m-labelled diethylene triamine pentacetate (DTPA) clearance, is a strong predictor of lung function decline in SSc-ILD, even when lung disease severity is taken into account (2). Serum KL-6 (Krebs von den Lungen 6), a mucin-like glycoprotein expressed by type II pneumocytes (3), is also a marker of epithelial cell damage, upregulated in SSc-ILD and in other ILDs. In SSc-ILD, serum KL-6 is correlated with ILD presence, severity and activity (48). The finding of a tight link between epithelial cells markers and lung fibrosis suggests that damage to alveolar epithelial cells is likely to play a fundamental role, at least in a subset of patients. This highlights the need to focus on potential noxious factors for the respiratory epithelium as potential drivers of the progression of lung fibrosis.

Gastro-esophageal reflux (GER) has been suggested as a driving factor in the pathogenesis of both SSc-ILD and idiopathic pulmonary fibrosis (IPF), the most frequent idiopathic form of lung fibrosis, with many similarities to SSc-ILD $(9,10)$. The esophagus is affected in $50-82 \%$ of patients with SSc (11). Gastric reflux may be liquid, gaseous, or particulate; acid or nonacid; distal (localized to the distal oesophagus) or proximal (reaching the proximal oesophagus and pharynx) (12). Reflux to the proximal oesophagus, which is intuitively linked to microaspiration into the lungs, appears to be quite common in patients with ILD-SSc and IPF
The finding of a tight link between epithelial cells markers and lung fibrosis suggests that damage to alveolar epithelial cells is likely to play a fundamental role, at least in a subset of patients with SScILD. 
$(13,14)$. Importantly, a significant proportion of GER reflux is asymptomatic (15).

\section{The role of pepsin}

Repeated episodes of microaspiration of gastric contents secondary to GER could lead to alveolar epithelial injury and subsequent fibrosis. The histopathological characteristics of microaspiration-related changes have been poorly studied. Bronchiolocentric organizing

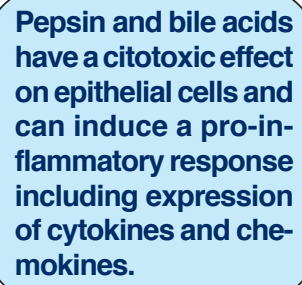

pneumonia, foreign bodies, intraluminal basophilic content have been described in surgical lung biopsies of ILD-SSc with possible microaspiration $(16,17)$. However, those histological features probably represent a small subgroup of ILD-SSc, while the vast majority of these patients show "pure" non specific interstitial pneumonia (NSIP) histopathologic pattern and GER is virtually present in all.

In addition to the well reported clinical association between GER in SSc and lung involvement (18-20), data from animal models and in vitro analysis have provided a biologic rationale supporting the role of microaspiration in the genesis and/or progression of ILD. Pepsin and bile acids have a citotoxic effect on epithelial cells and can induce a pro-inflammatory response including expression of cytokines and chemokines (21-23). In a rat model of chronic aspiration, interstitial pneumonitis changes followed the instillation into the airways of either whole gastric or neutralized gastric fluid, but not of hydrochloric acid (24). Indeed the fact that the refluxate loses its acidity when it approaches the proximal esophagus, may suggest that pepsin or other proteins found in the stomach content, instead of the acidity, are causative agents of lung fibrosis. Pepsin is inactive in an alkaline environment, but it remains stable and can reactivate when exposed again to acid (other reflux episodes) or taken up within epithelial cells by endocytosis (25).

However, it is important to bear in mind that GER is frequent in a number of chronic lung diseases and could simply be related to greater variation in the intrathoracic pressures, as the lung compliance worsens with disease progression (26). Indeed, it has been particularly difficult to ascertain how much GER is a consequence of lung disease severity, rather than a driver of lung disease progression.

\section{Gastro-esophageal reflux and ILD severity and pro- gression}

The majority of studies performed in SSc so far have used indirect methods to assess microaspiration into the lungs and have not clearly discriminated between ILD severity and progression. Of note, no study has looked for direct evidence of microaspiration into the lungs of SSc patients. Indeed GER should be considered a risk factor of microaspiration since only a proportion of reflux episodes can reach the airways.

Concentration of pepsin and bile acids in bronchoalveolar lavage (BAL) and exhaled breath condensate
(EBC) have been investigated as biomarkers of microaspiration in various respiratory diseases. The first studies linking BAL pepsin and bile salts with acid reflux episodes were performed in children $(27,28)$. More recently, elevated $\mathrm{BAL}$ bile salt concentrations have been associated with early onset of bronchiolitis obliterans in 120 post lung transplant patients (29). In the two studies performed so far on BAL pepsin levels
Notably, though virtually all SSc patients are on anti-reflux medications, henceforth no study have investigated the role of those medications on ILD-SSc. in fibrotic lung diseases, BAL pepsin was associated with acute exacerbations (30) and severity of lung fibrosis (13) in IPF patients. Of note, the latter study by Savarino et al. has shown similar results of BAL and saliva pepsin analysis in terms of correlation with lung function (13). Although saliva measurements is mainly a surrogate marker of microaspiration, this method is non-invasive and easily repeatable. A non-invasive direct test of microaspiration is EBC pepsin. EBC, an evolving method to test pulmonary diseases (31), is easily collected asking the patient to breath comfortably in a cold cylinder for 10 minutes. Raised levels of EBC pepsin have been associated with extra-pulmonary manifestations of GER in COPD (32), postlung transplant (33), IPF (34). However, all these studies are small and some have been presented only in the form of abstract.

As mentioned previously, a number of studies have suggested a link between severity of SSc-ILD and GER. Marie et al. observed that patients with severe esophageal dysfunction on manometry had a significantly lower diffusing capacity of the lung for carbon monoxide (DLCO) and a higher frequency of ILD on $\mathrm{CT}$, compared to those with mild or no esophageal involvement (35). Similarly, Savarino et al. reported that SSc patients with HRCT evidence of interstitial lung disease had a higher frequency of acid and non-acid reflux and a greater proportion of proximal reflux episodes, compared to those without ILD (14). However, it remains unclear whether GER is a risk factor for ILD progression. In the prospective study of 43 SSc patients by Marie et al., at two years from baseline, average fall in DLCO was $18 \%$ in those with severe esophageal dysfunction compared to $2 \%$ in the others (35). In a retrospective evaluation of 1043 SSc patient, GER symptoms and history of esophageal dilatation were predictive of ILD progression (20). By contrast, in another prospective study by Gilson et al., only a trend bordering on statistical significance was observed on univariate analysis between severe esophageal dysfunction and reduction in forced expiratory volume (FVC) at follow-up, which was not maintained after adjustment for disease severity, although only $7 \%$ of patients had extensive ILD involvement at baseline $(\mathrm{FVC}<70 \%)(36)$. Troshinsky et al. did not find a correlation between lung function and distal and/or proximal reflux in 39 consecutive SSc patients (37). In IPF, recent large retrospective analyses $(38,39)$ and a number of case series have suggested a link between GER 
suppression and better outcome (40, 41). The larger study that retrospectively analyzed 242 IPF patients assigned to receive placebo in previous randomized clinical trials, found a significant association between reported use of anti-acid medications and slower FVC deterioration (38). The Authors suggested that clinical trials testing the role of anti-GER therapies in IPF are warranted (38). Notably, though virtually all SSc patients are on anti-reflux medications, henceforth no study have investigated the role of those medications on ILD-SSc.

\section{Therapeutic implications and conclusions}

The confirmation of a causative link of microaspiration in the genesis and progression of lung fibrosis would have a major impact in the management of ILD-SSc patients. As discussed above, it is likely that proteas-

Anti-reflux surgery
has a variable outco-
me in SSc; however
a carefully selected
subgroup of patients
could be eligible for
fundoplication if this
could prevent lung fi-
brosis.
es such as pepsin, and not the acidity, are the primary target for future therapies. Potent inhibitors specific for proteases, e.g. pepstatin, are available and have been tested in phase-III clinical trials (42). Anti-reflux surgery has a variable outcome in SSc; however a carefully selected subgroup of patients could be eligible for fundoplication if this could prevent lung fibrosis. It is clear that prospective studies to assess prevalence and characteristics of microaspiration among SSc patients with ILD are required. This information could be crucial in order to highlight patients at greater risk of disease progression and to plan for appropriately designed interventional studies on the effectiveness of anti-GER treatments.

\section{References}

1. Renzoni EA. Interstitial lung disease in systemic sclerosis. Monaldi Arch. Chest Dis. 2007; 67(4):21728.

2. Goh NSL, Desai SR, Anagnostopoulos C, Hansell DM, Hoyles RK, Sato H, Denton CP, Black CM, du Bois RM, Wells AU. Increased epithelial permeability in pulmonary fibrosis in relation to disease progression. Eur Respir. J. 2011;38(1):184-90.

3. Kohno N, Kyoizumi S, Awaya Y, Fukuhara H, Yamakido M, Akiyama M. New serum indicator of interstitial pneumonitis activity. Sialylated carbohydrate antigen KL-6. Chest. 1989;96(1):68-73.

4. Hant FN, Ludwicka-Bradley A, Wang H-J, Li N, Elashoff R, Tashkin DP, Silver RM. Surfactant protein $\mathrm{D}$ and $\mathrm{KL}-6$ as serum biomarkers of interstitial lung disease in patients with scleroderma. J Rheumatol. 2009;36(4):773-80.

5. Yanaba K, Hasegawa M, Hamaguchi Y, Fujimoto M, Takehara K, Sato S. Longitudinal analysis of serum KL-6 levels in patients with systemic sclerosis: association with the activity of pulmonary fibrosis. Clin Exp. Rheumatol. 2003;21(4):429-36.
6. Okada M, Suzuki K, Matsumoto M, Nakashima M, Nakanishi T, Takada K, Horikoshi H, Matsubara O, Ohsuzu F. Intermittent intravenous cyclophosphamide pulse therapy for the treatment of active interstitial lung disease associated with collagen vascular diseases. Mod. Rheumatol. 2007;17(2):131-6.

7. Yamane K, Ihn H, Kubo M, Yazawa N, Kikuchi K, Soma Y, Tamaki K. Serum levels of KL-6 as a useful marker for evaluating pulmonary fibrosis in patients with systemic sclerosis. J Rheumatol. 2000;27(4): 930-4.

8. Yanaba K, Hasegawa M, Takehara K, Sato S. Comparative study of serum surfactant protein-D and KL6 concentrations in patients with systemic sclerosis as markers for monitoring the activity of pulmonary fibrosis. J Rheumatol. 2004;31(6):1112-20.

9. Raghu G, Freudenberger TD, Yang S, Curtis JR, Spada C, Hayes J, Sillery JK, Pope CE, Pellegrini CA. High prevalence of abnormal acid gastro-oesophageal reflux in idiopathic pulmonary fibrosis. Eur Respir J. 2006;27(1):136-42.

10. Lee JS, Collard HR, Raghu G, Sweet MP, Hays SR, Campos GM, Golden JA, King TE. Does chronic microaspiration cause idiopathic pulmonary fibrosis? Am. J. Med. 2010;123(4):304-11.

11. Thoua NM, Bunce C, Brough G, Forbes A, Emmanuel AV, Denton CP. Assessment of gastrointestinal symptoms in patients with systemic sclerosis in a UK tertiary referral centre. Rheumatology (Oxford). 2010;49(9):1770-5.

12. Kempainen RR, Savik K, Whelan TP, Dunitz JM, Herrington CS, Billings JL. High prevalence of proximal and distal gastroesophageal reflux disease in advanced COPD. Chest. 2007;131(6):1666-71.

13. Savarino E, Carbone R, Marabotto E, Furnari M, Sconfienza L, Ghio M, Zentilin P, Savarino V. Gastrooesophageal reflux and gastric aspiration in idiopathic pulmonary fibrosis patients. Eur Respir J. 2013;42(5):1322-31.

14. Savarino E, Bazzica M, Zentilin P, Pohl D, Parodi A, Cittadini G, Negrini S, Indiveri F, Tutuian R, Savarino V, Ghio M. Gastroesophageal reflux and pulmonary fibrosis in scleroderma: a study using $\mathrm{pH}$-impedance monitoring. Am J Respir Crit Care Med. 2009; 179(5):408-13.

15. Fass R, Sampliner RE. Barrett's esophagus and other mucosal evidence of reflux in asymptomatic subjects with abnormal 24-hour esophageal pH monitoring. Dig Dis Sci. 1994;39(2):423-5.

16. Barnes TW, Vassallo R, Tazelaar HD, Hartman TE, Ryu JH. Diffuse bronchiolar disease due to chronic occult aspiration. Mayo Clin. Proc. 2006;81 (2):172-6.

17. de Souza RBC, Borges CTL, Capelozzi VL, Parra ER, Jatene FB, Kavakama J, Kairalla RA, Bonfá E. Centrilobular fibrosis: an underrecognized pattern in sys temic sclerosis. Respiration. 2009;77(4):389-97.

18. Lock G, Pfeifer M, Straub RH, Zeuner M, Lang B, Schölmerich J, Holstege A. Association of esophageal dysfunction and pulmonary function impairment in systemic sclerosis. The American journal of gastroenterology. 1998;93(3):341-5. 
19. Kinuya K, Nakajima K, Kinuya S, Michigishi T, Tonami $\mathrm{N}$, Takehara K. Esophageal hypomotility in systemic sclerosis: close relationship with pulmonary involvement. Ann Nucl Med. 2001;15(2):97-101.

20. Zhang XJ, Bonner A, Hudson M, Baron M, Pope J. Association of gastroesophageal factors and worsening of forced vital capacity in systemic sclerosis. J Rheumatol. 2013;40(6):850-8.

21. Appel JZ, Lee SM, Hartwig MG, Li B, Hsieh C-C, Cantu E, Yoon Y, Lin SS, Parker W, Davis RD. Characterization of the innate immune response to chronic aspiration in a novel rodent model. Respir Res. 2007;8: 87.

22. Perng D-W, Chang K-T, Su K-C, Wu Y-C, Wu M-T, Hsu W-H, Tsai C-M, Lee Y-C. Exposure of airway epithelium to bile acids associated with gastroesophageal reflux symptoms: a relation to transforming growth factor-beta1 production and fibroblast proliferation. Chest. 2007;132(5):1548-56.

23. Bathoorn E, Daly P, Gaiser B, Sternad K, Poland C, Macnee W, Drost EM. Cytotoxicity and induction of inflammation by pepsin in Acid in bronchial epithelial cells. Int J Inflam. 2011;2011:569416.

24. Downing TE, Sporn TA, Bollinger RR, Davis RD, Parker W, Lin SS. Pulmonary histopathology in an experimental model of chronic aspiration is independent of acidity. Exp Biol Med. (Maywood). 2008;233(10):1202-12.

25. Bardhan KD, Strugala V, Dettmar PW. Reflux revisited: advancing the role of pepsin. Int J Otolaryngol. 2012;2012:646901.

26. Brennan NJ, Morris AJ, Green M. Thoracoabdominal mechanics during tidal breathing in normal subjects and in emphysema and fibrosing alveolitis. Thorax. 1983;38(1):62-6.

27. Starosta V, Kitz R, Hartl D, Marcos V, Reinhardt D, Griese M. Bronchoalveolar pepsin, bile acids, oxidation, and inflammation in children with gastroesophageal reflux disease. Chest. 2007;132(5):155764.

28. Farrell S, McMaster C, Gibson D, Shields MD, McCallion WA. Pepsin in bronchoalveolar lavage fluid: a specific and sensitive method of diagnosing gastrooesophageal reflux-related pulmonary aspiration. J Pediatr Surg. 2006;41(2):289-93.

29. D'Ovidio F, Mura M, Tsang M, Waddell TK, Hutcheon MA, Singer LG, Hadjiliadis D, Chaparro C, Gutierrez C, Pierre A, Darling G, Liu M, Keshavjee S. Bile acid aspiration and the development of bronchiolitis obliterans after lung transplantation. J Thorac Cardiovasc Surg. 2005;129(5):1144-52.

30. Lee JS, Song JW, Wolters PJ, Elicker BM, King TE, Kim DS, Collard HR. Bronchoalveolar lavage pepsin in acute exacerbation of idiopathic pulmonary fibrosis. Eur Respir J. 2012;39(2).352-8.
31. Ahmadzai H, Huang S, Hettiarachchi R, Lin J-L, Thomas PS, Zhang Q. Exhaled breath condensate: a comprehensive update. Clin Chem Lab Med. 2013;51(7):1343-61.

32. Timms C, Thomas PS, Yates DH. Detection of gastro-oesophageal reflux disease (GORD) in patients with obstructive lung disease using exhaled breath profiling. J Breath Res. 2012;6(1):016003.

33. Krishnan DHYA, Chow S, Thomas PS, Malouf MA, Glanville AR. Exhaled breath condensate pepsin: a new noninvasive marker of GERD after lung transplantation. J Hear Lung Transplant. 2007;26(2S): S139.

34. Fahim A, Dettmar PW, Morice AH, Hart SP. Gastroesophageal reflux and idiopathic pulmonary fibrosis: a prospective study. Medicina (Kaunas). 2011;47(4): 200-5.

35. Marie I, Dominique S, Levesque H, Ducrotté P, Denis $\mathrm{P}$, Hellot MF, Courtois H. Esophageal involvement and pulmonary manifestations in systemic sclerosis. Arthritis Rheum. 2001;45(4):346-54.

36. Gilson M, Zerkak D, Wipff J, Dusser D, Dinh-Xuan AT, Abitbol V, Chaussade S, Legmann P, Kahan A, Allanore $Y$. Prognostic factors for lung function in systemic sclerosis: prospective study of 105 cases. Eur Respir J. 2010;35(1):112-7

37. Troshinsky MB, Kane GC, Varga J, Cater JR, Fish JE, Jimenez SA, Castell DO. Pulmonary function and gastroesophageal reflux in systemic sclerosis. Ann Intern Med. 1994;121(1): 6-10.

38. Lee JS, Collard HR, Anstrom KJ, Martinez FJ, Noth I, Roberts RS, Yow E, Raghu G. Anti-acid treatment and disease progression in idiopathic pulmonary fibrosis: an analysis of data from three randomised controlled trials. Lancet Respir Med. 2013;1(5):36976.

39. Lee JS, Ryu JH, Elicker BM, Lydell CP, Jones KD, Wolters PJ, King TE, Collard HR. Gastroesophageal reflux therapy is associated with longer survival in patients with idiopathic pulmonary fibrosis. Am J Respir Crit Care Med. 2011;184(12):1390-4.

40. Raghu G, Weycker D, Edelsberg J, Bradford WZ, Oster $\mathrm{G}$. Incidence and prevalence of idiopathic pulmonary fibrosis. Am J Respir Crit Care Med. 2006;174(7):810-6.

41. Linden PA, Gilbert RJ, Yeap BY, Boyle K, Deykin A, Jaklitsch MT, Sugarbaker DJ, Bueno R. Laparoscopic fundoplication in patients with end-stage lung disease awaiting transplantation. J Thorac Cardiovasc Surg. 2006;131(2): 438-46.

42. Bonnevie O, Svendsen LB, Holst-Christensen J, Johansen TS, Søltoft J, Christiansen PM. Double-blind randomised clinical trial of a pepsin-inhibitory pentapeptide (pepstatin) in the treatment of duodenal ulcer. Gut. 1979;20(7):624-8. 